\title{
Apoptosis Versus Oncotic Necrosis in Hepatic Ischemia/Reperfusion Injury
}

\author{
HARTMUT JAESCHKE* and JOHN J. LEMASTERS ${ }^{\dagger}$ \\ * Liver Research Institute, University of Arizona, Tucson, Arizona; and ${ }^{\ddagger}$ Department of Cell and Developmental Biology, University of North \\ Carolina, Chapel Hill, North Carolina
}

Warm and cold hepatic ischemia followed by reperfusion leads to necrotic cell death (oncosis), which often occurs within minutes of reperfusion. Recent studies also suggest a large component of apoptosis after ischemia/reperfusion. Here, we review the mechanisms underlying adenosine triphosphate depletion-dependent oncotic necrosis and caspase-dependent apoptosis, with emphasis on shared features and pathways. Although apoptosis causes internucleosomal DNA degradation that can be detected by terminal deoxynucleotidyl transferase-mediated deoxyuridine triphosphate nick-end labeling and related assays, DNA degradation also occurs after oncotic necrosis and leads to pervasive terminal deoxynucleotidyl transferase-mediated deoxyuridine triphosphate nick-end labeling staining far in excess of that for apoptosis. Similarly, although apoptosis can occur in a physiological setting without inflammation, in pathophysiological settings apoptosis frequently induces inflammation because of the onset of secondary necrosis and stimulation of cytokine and chemokine formation. In liver, the mitochondrial permeability transition represents a shared pathway that leads to both oncotic necrosis and apoptosis. When the mitochondrial permeability transition causes severe adenosine triphosphate depletion, plasma membrane failure and necrosis ensue. If adenosine triphosphate is preserved, at least in part, cytochrome $c$ release after the mitochondrial permeability transition activates caspasedependent apoptosis. Mitochondrial permeability transition-dependent cell death illustrates the concept of necrapoptosis, whereby common pathways lead to both necrosis and apoptosis. In conclusion, oncotic necrosis and apoptosis can share features and mechanisms, which sometimes makes discrimination between the 2 forms of cell death difficult. However, elucidation of critical cell death pathways under clinically relevant conditions will show potentially important therapeutic intervention strategies in hepatic ischemia/reperfusion injury.

$\mathrm{H}$ epatic ischemia/reperfusion injury occurs in diverse circumstances, including liver surgery (e.g., a Pringle maneuver during tumor resection or liver trauma), liver preservation for transplantation, veno-occlusive disease, hemorrhagic shock-resuscitation, and heart failure. Different injury mechanisms contribute to the overall pathophysiology of hepatic ischemia/reperfusion injury. ${ }^{1-6}$ Although ischemic stress itself primes cells for damage and will eventually cause cell death, cell injury often does not manifest itself until after the ischemic liver is reperfused. ${ }^{7}$

Production of reactive oxygen species, including superoxide, hydrogen peroxide, and hydroxyl radicals, has long been implicated in reperfusion injury, but oxygenindependent factors are important as well, such as tissue $\mathrm{pH}$ changes during ischemia/reperfusion. ${ }^{8}$ Inflammatory responses ${ }^{2,6}$ and microcirculatory problems ${ }^{4}$ further aggravate injury after reperfusion. Ischemia/reperfusion activates Kupffer cells, the resident macrophages of the liver, and functional inactivation of Kupffer cells attenuates injury during early and late reperfusion. ${ }^{9-13}$ Kupffer cells activated after reperfusion generate reactive oxygen species, proinflammatory cytokines, chemokines, and other mediators that contribute to postischemic tissue injury and to the systemic inflammatory response syndrome and multiorgan failure that may follow a severe ischemic insult to the liver. ${ }^{14}$ Together with activated complement factors, ${ }^{15}$ these inflammatory mediators activate and recruit neutrophils into the postischemic liver, ${ }^{16,17}$ which generates even more reactive oxygen ${ }^{18,19}$ and releases additional proteases and other degradative enzymes. ${ }^{20}$ In addition to the inflammatory response, vasoconstriction of sinusoids induced by endothelin-121 promotes heterogeneous closure of many microvessels, which prolongs ischemia in certain areas of the liver even after reperfusion. ${ }^{22}$

\footnotetext{
Abbreviations used in this paper: IкB, inhibitor of nuclear factor $\kappa \mathrm{B}$; MPT, mitochondrial permeability transition; NFKB, nuclear factor-кB; TNF, tumor necrosis factor; TUNEL, terminal deoxynucleotidyl transferase-mediated deoxyuridine triphosphate nick-end labeling.

(C) 2003 by the American Gastroenterological Association $0016-5085 / 03 / \$ 30.00$ doi:10.1053/S0016-5085(03)01209-5
} 
Most of the described mechanisms of reperfusion injury generally assume cell damage that involves oncotic necrosis. However, several recent reports propose that apoptosis occurs in postischemic heart, liver, and other tissues. ${ }^{23-25}$ Postischemic apoptosis would seem to contradict earlier findings of necrotic cell death. Thus, confusion and uncertainty exist concerning the actual mode of cell killing after ischemia/reperfusion. Accordingly, the goal of this overview is to discuss the distinctions between apoptosis and necrosis and to evaluate critically the methods and approaches used to quantify apoptotic and necrotic cell death to reach conclusions regarding the pathophysiological role of each mode of cell death in hepatic ischemia/reperfusion injury.

\section{Oncotic Necrosis (Oncosis) in Ischemia/Reperfusion Injury}

The primary stress in ischemia to liver and most other solid tissues is loss of mitochondrial adenosine triphosphate (ATP) production. The resulting ATP depletion leads to cellular swelling, rounding and swelling of mitochondria, dilatation of the endoplasmic reticulum, and formation of plasma membrane protrusions called blebs. ${ }^{26,27}$ Blebs are a consequence of ATP depletion and likely represent a response to disrupted cellular volume control and cytoskeletal disturbances. After briefer periods of ischemia/anoxia, bleb formation rapidly reverses after reoxygenation, but necrotic cell death occurs after longer periods. Just before cell death, hepatocytes and hepatic sinusoidal cells develop a metastable state, which is characterized by mitochondrial permeabilization, lysosomal disruption, bleb coalescence and growth, cell swelling, and leakage of anionic solutes. ${ }^{28-30}$ Opening of glycine-sensitive anion channels that conduct chloride and various organic anions initiates the metastable state and a phase of rapid colloid osmotic swelling. ${ }^{30}$ Cell death then occurs by failure of the plasma membrane permeability barrier, often caused by bleb rupture. ${ }^{28,29}$ Plasma membrane permeabilization causes release of cellular enzymes and other contents, labeling with vital dyes such as trypan blue, and development of histological changes known as necrosis. The release of cellular contents also initiates an inflammatory response during reperfusion. Over time, macrophages gradually resorb the remnants of the necrotic tissue, which is replaced by scar tissue. Taken together, the observations of postischemic cell swelling, vacuolation, karyolysis, and cell content release, affecting cells in large areas of the tissue in combination with a substantial inflammatory response, are characteristic features of a necrotic cell death process, more recently renamed oncosis or oncotic necrosis. ${ }^{31}$

\section{Morphological Features of Apoptosis}

The original description of apoptotic cell death was based on morphology. ${ }^{32}$ The classic morphological features of apoptosis include cellular shrinkage, nuclear condensation, chromatin margination, and fragmentation of both the nucleus and cytoplasm into apoptotic bodies, which are phagocytosed and degraded by phagocytes, neighboring cells, or both (Figure 1). The original definition of apoptosis describes the cytoplasmic organelles of apoptotic cells as remaining normal in appearance, in marked contrast to necrosis, although many more recent studies show mitochondrial swelling, changes to the endoplasmic reticulum, increased autophagy, and other cytoplasmic changes during apoptosis. ${ }^{33}$ In classic apoptotic cell death, intracellular contents are not released, and a consequent inflammatory response fails to develop. Functionally, apoptosis eliminates excess and unneeded cells during development and damaged and worn-out cells during normal tissue turnover. Characteristically, apoptosis affects individual isolated cells in a tissue, rather than groups of contiguous cells. Under certain conditions, the apoptotic cell death program may not go to completion. Instead, secondary necrosis supervenes, resulting in the release of proinflammatory intracellular contents. ${ }^{34}$

\section{Signaling Mechanisms in Hepatocellular Apoptosis}

We first briefly review some basic background information on apoptotic signaling pathways in hepatocytes to place into context the discussion of whether postischemic cell death is caused by apoptosis. During the last decade, dramatic progress has been made in the elucidation of the intracellular signaling mechanisms of apoptosis. ${ }^{35-39}$ A variety of mediators, including tumor necrosis factor (TNF)- $\alpha$, Fas ligand, and tumor necrosis factor-related apoptosis-inducing ligand (TRAIL), activate a so-called extrinsic pathway to apoptosis. As illustrated for TNF- $\alpha$ in Figure 2, these proapoptotic mediators first bind to their respective receptors, which cause receptor oligomerization and the association of various adapter proteins, including Fas-associated death domain, TNF- $\alpha$ receptor-associated death domain, and TNF- $\alpha$ receptor-associated factor. Fas-associated death domain and TNF- $\alpha$ receptor-associated death domain promote binding of procaspase 8 and its proteolytic activation to catalytic caspase 8 . If sufficient amounts of caspase 8 are 


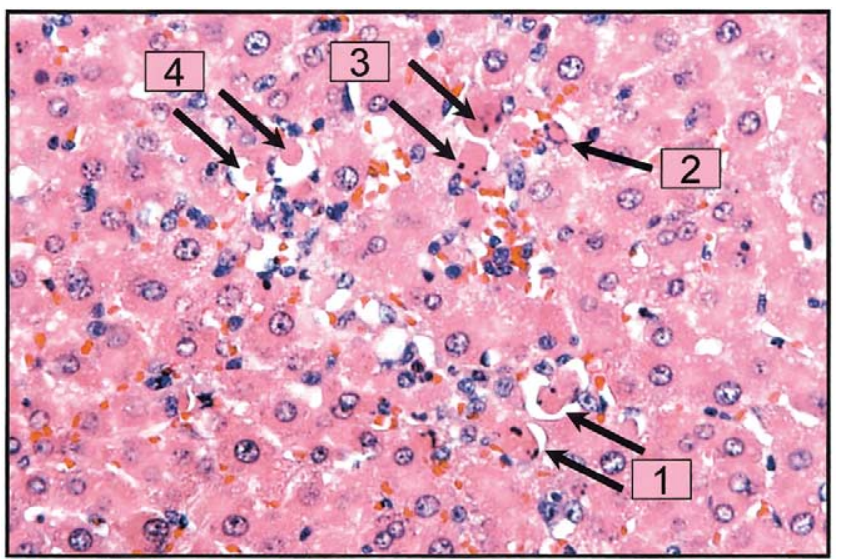

Figure 1. Liver histology of galactosamine-induced apoptosis. Characteristic morphology is shown of rat hepatocytes undergoing apoptotic cell death 6 hours after treatment with galactosamine $(500 \mathrm{mg} /$ $\mathrm{kg})$. Features of apoptosis include cell shrinkage (1), chromatin margination (2), chromatin condensation and fragmentation (3), and formation of apoptotic bodies (4).

generated at the receptor, caspase 8 can directly activate procaspase 3 (type 1 pathway). ${ }^{40}$ However, in hepatocytes, the receptor signal needs to be amplified through mitochondria (type 2 pathway). ${ }^{40,41}$ Caspase 8 cleaves Bid, a BH3 domain-only Bcl-2 family member, to an active fragment, $t \mathrm{Bid}$, which translocates to mitochondria. $t$ Bid translocation leads to release of soluble proteins from mitochondria that activate caspases and initiate apoptotic nuclear changes. ${ }^{41}$ These protein factors include cytochrome $c$, apoptosis-inducing factor, and Smac/Diablo, which reside in the intermembrane space

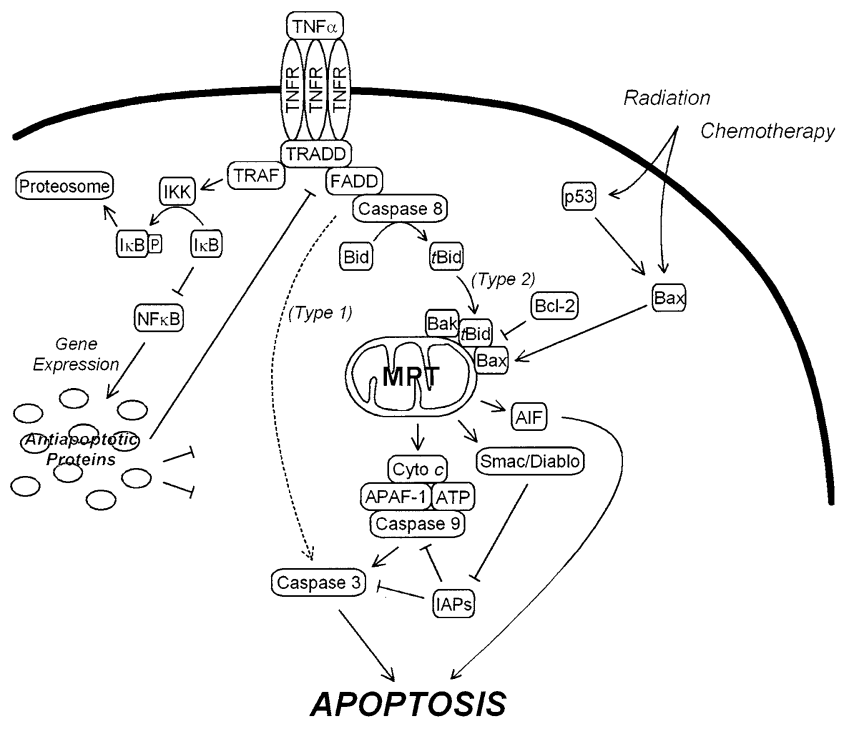

Figure 2. Scheme of apoptotic signaling in hepatocytes. AIF, apoptosis-inducing factor; APAF-1, apoptosis-activating factor-1; IKK, ІкB kinase; TRADD, tumor necrosis factor- $\alpha$ receptor-associated death domain; TRAF, tumor necrosis factor- $\alpha$ receptor-associated factor. between the mitochondrial inner and outer membranes. ${ }^{42-45}$

The mechanisms that induce the release of mitochondrial intermembrane proteins remain controversial. In hepatocytes, TNF- $\alpha$ - and Fas-dependent signaling induces the onset of the mitochondrial permeability transition (MPT). The MPT occurs from the opening of a pore, the permeability transition pore, which is highly conductive to solutes of molecular weight up to approximately 1500 daltons. ${ }^{46}$ As a consequence of permeability transition pore opening, mitochondria depolarize, uncouple, and undergo large amplitude swelling. This
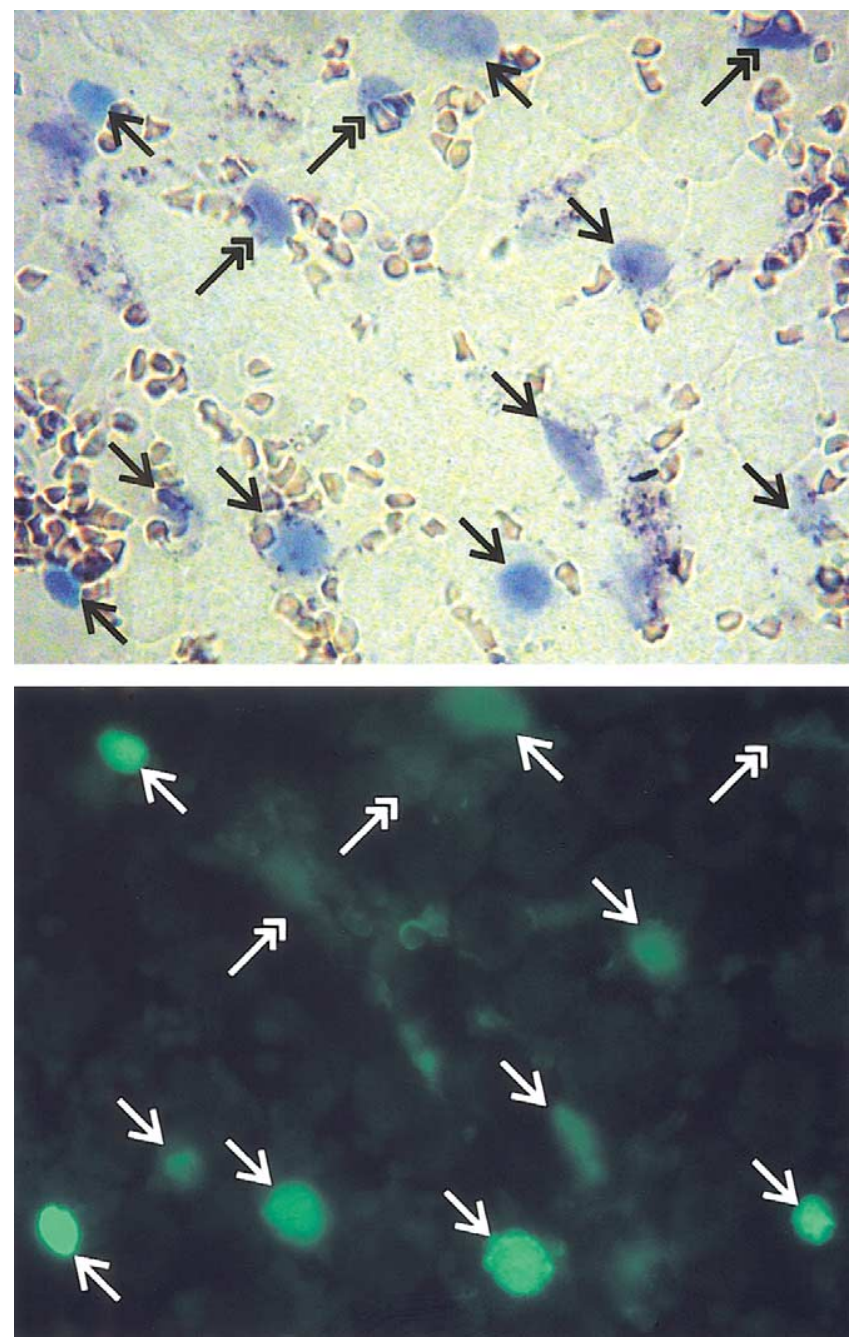

Figure 3. Trypan blue staining and TUNEL labeling after cold liver storage and orthotopic rat liver transplantation. A rat liver was stored in cold University of Wisconsin solution for 44 hours and transplanted into a recipient rat. After 15 minutes of implantation, the liver graft was infused with trypan blue and fixed. The upper panel shows trypan blue uptake into the nuclei of nonviable cells, indicating oncotic necrosis, whereas the lower panel shows TUNEL-positive nuclei labeled with green fluorescence, indicating DNA strand breaks. Note that all TUNEL-positive cells stain with trypan blue (arrows), whereas some trypan blue-labeled cells stain weakly or not at all with TUNEL (double arrows). (X.-X. Peng, et al., unpublished data, January 2003). 
swelling causes a rupture of the outer membrane and a release of proteins from the intermembrane space. Other mechanisms for cytochrome $c$ release also seem to exist. In some models, $t \mathrm{Bid}$ interaction with either $\mathrm{Bax}$ or $\mathrm{Bak}$, 2 other proapoptotic members of the Bcl-2 family, forms channels in the mitochondrial outer membrane that release cytochrome $c$ and a number of other, larger proteins from the intermembrane space. The nature and composition of these channels, however, remain poorly understood. ${ }^{43,47,48} \mathrm{Bcl}-2$ and other antiapoptotic Bcl-2 family members block cytochrome $c$ release. The mechanism for the antiapoptotic action of $\mathrm{Bcl}-2$ may involve blockade of the MPT and/or antagonism of Bax/Bak-dependent pore formation in the mitochondrial outer membrane.

After its release from mitochondria, cytochrome $c$ forms a complex with apoptosis-activating factor-1, ATP (or deoxyadenosine triphosphate), and procaspase 9 (Figure 2). This complex, called an apoptosome, proteolytically activates caspase 9, which in turn activates procaspase 3 to caspase 3.49 Through action on a variety of substrates, caspase 3 activity initiates the final execution stages of apoptosis, including cell shrinkage, surface blebbing, internucleosomal DNA hydrolysis, phosphatidyl serine externalization on the plasma membrane, chromatin margination, and nuclear lobulation.

In general, the type 2 apoptotic signaling pathway through the mitochondria, as it occurs in hepatocytes, is faster than the type 1 pathway and can be better regulated. However, if the type 2 pathway is blocked by inhibition of the MPT with cyclosporin A, caspase 3 activation and apoptosis will still occur, but at a slower rate, via a type 1 pathway, but without mitochondrial depolarization, the MPT, or cytochrome $c$ release (Figure 2). ${ }^{50}$ Adding to this redundancy is the so-called intrinsic pathway to apoptosis ${ }^{51}$ (Figure 2). Such pathways may or may not involve p53-dependent gene expression but may activate apoptosis by still incompletely understood mechanisms through translocation of Bax and other proapoptotic Bcl-2 family members to the mitochondria to cause cytochrome $c$ release and the activation of caspases 9 and 3 .

Death receptors also initiate survival signals. For example, ligation and oligomerization of TNF- $\alpha$ receptors and Fas promote receptor association of another adapter protein, TNF- $\alpha$ receptor-associated factor. TNF- $\alpha$ receptor-associated factor in turn initiates inhibitor of nuclear factor- $\kappa \mathrm{B}(\mathrm{I \kappa} \mathrm{B})$ kinase activation, ІкB phosphorylation, and subsequent degradation of ІкB in proteosomes. The disappearance of $\mathrm{I} \kappa \mathrm{B}$ de-represses nuclear factor- $\kappa \mathrm{B}(\mathrm{NF \kappa} \mathrm{B})$, which translocates to the nucleus to induce expression of several antiapoptotic genes that prevent apoptosis from occurring, including inhibitorof-apoptosis proteins (Figure 2). ${ }^{52,53}$ Survival signaling through $\mathrm{NF \kappa B}$ is so strong that to induce apoptosis in cultured hepatocytes, NFKB-dependent gene expression must be blocked by using protein or messenger RNA synthesis inhibitors or by expressing an IкB superrepressor that has been mutated to lack a phosphorylation site for IкB kinase. ${ }^{54}$

\section{Assessment of Apoptotic Cell Death}

As a result of an increasing understanding of the mechanisms and pathways to apoptotic cell death, more and more biochemical and immunologic assays are being developed and used to characterize apoptosis (Table 1). Today, apoptosis can be monitored in vitro and in vivo

Table 1. Assays for Apoptosis

Nuclear morphology (chromatin condensation and nuclear lobulation/fragmentation) in histological sections and after fluorescent staining with DAPI, propidium iodide, and so on

Internucleosomal DNA cleavage (DNA ladder after starch gel electrophoresis; ELISA for DNA fragments)

TUNEL and related assays (in situ detection of double-stranded DNA breaks)

Annexin V (phosphatidyl serine externalization)

Caspase assays (especially caspases $3,2,8$, and 9)

Enzyme assays using fluorogenic substrates

Immunocytochemistry with specific antibodies against activated caspases

Western blotting to show a decrease of the proenzyme and the appearance of active fragments

Cleavage of caspase substrates (e.g., PARP cleavage)

Nuclear staining with supravital dyes for secondary necrosis (trypan blue; propidium iodide)

Mitochondrial depolarization assessed with potential-indicating fluorophores (rhodamine 123, tetramethylrhodamine methylester, JC-1, and so on)

Cytochrome $c$ release into cytosol (Western blot; immunocytochemistry)

Translocation of proapoptotic proteins (Bax, Bid, and so on) to mitochondria; proteolytic cleavage of Bid (Western blot; immunocytochemistry)

DAPI, 4',6-diamidino-2-phenylindole; ELISA, enzyme-linked immunosorbent assay; JC-1, 5,5',6,6'-tetrachloro-1,1',3,3'-tetraethylbenzimidazolyl carboxycyanine iodide. PARP, poly (adenosine diphosphate-ribose) polymerase. 
by such diverse techniques as enzyme assays for activated caspases, Western blot analyses for caspase processing, annexin $\mathrm{V}$ labeling for phosphatidyl serine externalization, cleavage of poly (adenosine diphosphate-ribose) polymerase and other targets of caspase 3 proteolytic action, trypan blue and propidium iodide staining, and mitochondrial depolarization and cytochrome $c$ release, in addition to classic morphological criteria. In particular, a distinctive form of random DNA cleavage between nucleosomes occurs in apoptosis, which produces DNA fragments in multiples of approximately 190 base pairs (the length of DNA from 1 nucleosome to the next). This pattern of DNA cleavage produces a characteristic laddering pattern after gel electrophoresis. Other methods to assess DNA cleavage are by enzyme-linked immunosorbent assay kits that detect DNA fragments and by the terminal deoxynucleotidyl transferase-mediated deoxyuridine triphosphate nick-end labeling (TUNEL) assay (Table 1).

It is important to note that apoptosis represents a constellation of events, and no single change is necessarily a required event in apoptosis or is unique to apoptosis. For example, mitochondrial depolarization, swelling, and cytochrome $c$ release also typically occur in oncotic necrosis, and the trypan blue and propidium iodide labeling of so-called late apoptosis actually represents a phenomenon of secondary necrosis associated with loss of plasma membrane integrity. Necrotic cell death also leads to annexin $\mathrm{V}$ labeling, ${ }^{55}$ because after lysis of the plasma membrane, annexin $\mathrm{V}$ gains entrance to the interior of cells and the internal surface of the plasma membrane, where phosphatidylserine normally resides. Caspase 3 activation is perhaps most uniquely associated with apoptosis, but not all forms of apoptosis require caspase 3 activation.

Necrosis also causes DNA cleavage, although such cleavage is not characteristically internucleosomal. On gel electrophoresis, such cleavage leads to a smear of many different molecular weight fragments rather than a ladder pattern of multiples of 190 base pairs. However, DNA fragmentation with a ladder pattern was also reported during necrosis. ${ }^{56,57}$ Calcium-dependent activation of endonucleases may be responsible for this effect. ${ }^{58}$ Techniques such as the TUNEL assay may not distinguish the internucleosomal DNA cleavage of apoptosis from the much less ordered DNA cleavage of necrosis. In liver and other tissues, TUNEL labeling occurs during ischemic necrosis and after toxicant-induced necrotic cell killing. ${ }^{59-61}$ Indeed, after reperfusion of livers stored for transplantation, the same cells showing TUNEL labeling, a presumptive indicator of apoptosis, also labeled with trypan blue, an indicator of oncotic necrosis, whereas not all trypan blue-stained cells labeled with TUNEL (Figure 3). These observations are consistent with postnecrotic DNA hydrolysis as the basis for TUNEL conversion in necrotic tissue, as previously proposed. ${ }^{59-61}$

Overall, the most reliable method to identify apoptotic cell death is morphology. Vital dyes and simple histology can readily visualize nuclear morphology (chromatin condensation and fragmentation). Once apoptosis as the mode of cell death is established by the characteristic morphological changes, any number of other parameters listed in Table 1 can be used to further support the hypothesis and delineate specific signaling pathways.

\section{Apoptotic Cell Death During Hepatic Ischemia/Reperfusion}

The first report of apoptotic cell death during hepatic ischemia/reperfusion appeared in 1996. ${ }^{24}$ Similar reports of postischemic apoptosis have appeared for heart, brain, and other organs. ${ }^{23,62,63}$ In liver after 60 minutes of warm ischemia, the number of apoptotic hepatocytes evaluated by nuclear morphology increases during the first 24 hours of reperfusion. ${ }^{24}$ Using the TUNEL assay, another study identified apoptotic hepatocytes in human allografts after transplantation. ${ }^{64}$ Subsequent studies reported that sinusoidal endothelial cells undergo apoptosis during cold ischemia/reperfusion ${ }^{25}$ and that both sinusoidal endothelial cells and hepatocytes undergo apoptosis after warm ischemia/reperfusion. ${ }^{65}$ These observations were based largely on fluorescence TUNEL assays and DNA laddering in gels. In addition, electron microscopy showed that single cells meet the morphological definition of apoptosis. ${ }^{25,65}$ Further, pancaspase inhibitors attenuated reperfusion injury after warm and cold ischemia. ${ }^{66,67}$ By the criteria of TUNEL labeling, $60 \%$ to $80 \%$ of sinusoidal endothelial cells and hepatocytes undergo apoptosis within 6 hours of reperfusion. ${ }^{65,67}$ Further studies suggested that Kupffer cells and platelets are responsible for inducing apoptosis in these liver cells through the release of TNF- $\alpha .{ }^{68,69}$

Despite the growing literature on apoptotic cell death after hepatic ischemia/reperfusion, concerns exist regarding the interpretation of these results and the relevance of apoptosis in the pathophysiology of reperfusion injury. The onset of necrotic cell death as judged by enzyme release and staining with trypan blue and propidium iodide occurs within minutes of reperfusion (see Figure 3). ${ }^{70-72}$ After warm ischemia, reperfusion-induced oncotic necrosis occurs predominantly in hepatocytes and is accompanied by enzyme release. ${ }^{71,73}$ After cold ischemia 
during liver preservation for transplantation, necrotic death occurs nearly exclusively in sinusoidal endothelial cells and is accompanied by relatively little enzyme release because of the much smaller cytoplasmic mass of the endothelial cells. ${ }^{7,70}$ The extent of this reperfusioninduced necrotic cell killing correlates well with graft failure after transplantation. When strict morphological criteria in combination with the TUNEL assay are used, apoptosis of endothelial cells and hepatocytes after 45 to 120 minutes of warm ischemia can be confirmed, but quantitatively apoptosis never exceeds $2 \%$ of the liver cells at risk. ${ }^{74}$ Furthermore, necrotic cell death, identified by cell swelling, karyorrhexis, karyolysis, and vacuolization, accounts for more than $90 \%$ of all cell death, although many of the necrotic cells are TUNEL positive. ${ }^{74}$ The relatively minor component of apoptotic cell death after reperfusion is consistent with several other reports. ${ }^{24,75-77}$ The limited amount of apoptotic cell death also correlates with limited or absent activation of caspases. ${ }^{74}$ In contrast, during Fas- and TNF receptorinduced apoptosis in vivo, which affects approximately $15 \%-30 \%$ of hepatocytes, caspase 3 activity levels increase 10- to 20-fold or more, and extensive processing of procaspase 3 occurs $^{78,79}$-features that are nearly absent after ischemia/reperfusion. ${ }^{74}$

Characteristically, apoptosis occurs in individual isolated cells. Even if large numbers of hepatocytes are induced in vivo to undergo apoptosis after activation of Fas or TNF receptors, individual cells rather than groups of contiguous cells show apoptotic features (Figure $4 B$ ). In contrast, oncotic necrosis typically occurs in confluent areas of adjacent cells (Figure $4 C$ and D). ${ }^{61,80,81}$ After

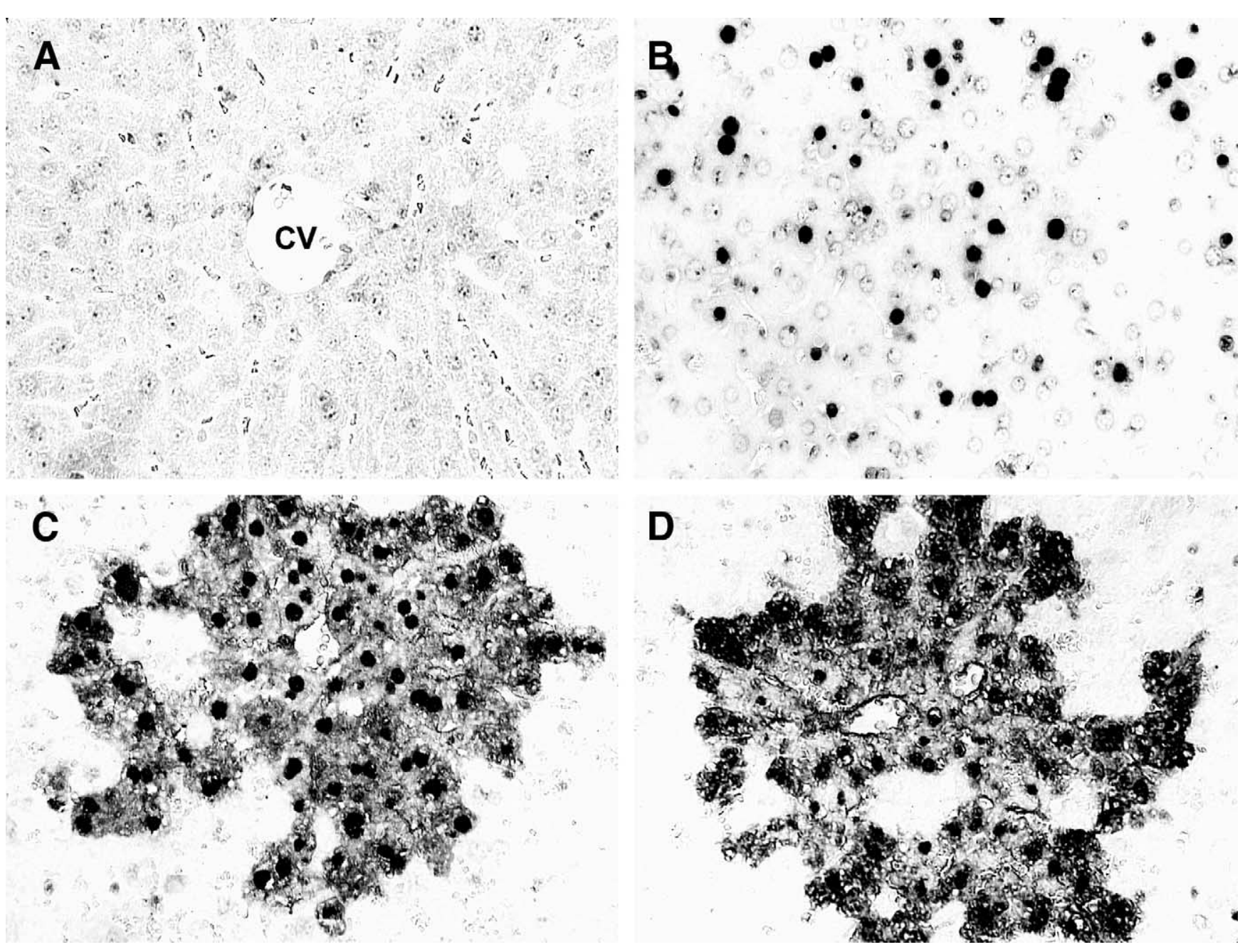

Figure 4. Hepatic TUNEL staining in TNF- $\alpha$-induced apoptosis and acetaminophen-induced oncotic necrosis. Mice were untreated $(A)$, received $700 \mathrm{mg} / \mathrm{kg}$ galactosamine and $100 \mu \mathrm{g} / \mathrm{kg}$ endotoxin for 6 hours $(B)$, or were treated with $300 \mathrm{mg} / \mathrm{kg}$ acetaminophen for 4 hours $(C)$ or 6 hours $(D)$. The assay shows a selective nuclear staining of individual hepatocytes during apoptosis $(B)$ compared with the nuclear/cytosolic staining of contiguous cells in the centrilobular region of early oncotic necrosis after acetaminophen $(C)$. Because of the more extensive karyolysis at later stages of oncotic necrosis, nuclear staining is less prominent in most cells compared with the cytosolic staining after 6 hours of acetaminophen treatment $(D)$. CV, central vein. 
hepatic ischemia/reperfusion, this necrosis typically occurs in the pericentral and midzonal regions of the hepatic lobule, because these regions are furthest removed from the oxygen supply. ${ }^{5,74}$ These observations are consistent with the conclusion that the main mode of cell death during reperfusion injury is oncotic necrosis.

Another argument for apoptosis as the principal mode of cell killing after ischemia/reperfusion is the protective effect of $\mathrm{Bcl}-2$ overexpression. ${ }^{82} \mathrm{Bcl}-2$ interrupts apoptotic signaling at the level of the mitochondria ${ }^{38}$ and prevents Fas-induced hepatocellular apoptosis. ${ }^{83}$ However, Bcl-2 overexpression also inhibits necrotic cell death in hepatocytes and other cell types, possibly by inhibiting the MPT. ${ }^{84,85}$ Oncosis can have other similarities to apoptosis, such as translocation of Bax to the mitochondria ${ }^{86}$ and release of mitochondrial cytochrome $c$ (without caspase 3 activation) ${ }^{87}$ during acetaminopheninduced oncotic necrosis. Thus, identification of apoptosis as the principal mode of cell death requires evaluation of several parameters, which should qualitatively and quantitatively correlate with the extent of the assumed apoptosis.

Despite the predominance of necrosis over apoptosis after hepatic ischemia/reperfusion, several groups report protection by caspase inhibitors during ischemia/reperfusion. ${ }^{6,67}$ However, protection may be rather modest, even with potent pancaspase inhibitors. For example, pancaspase inhibitors delay liver graft failure after prolonged cold ischemic storage by only approximately a day, without improvement of long-term graft survival. ${ }^{67}$ This small and ultimately clinically irrelevant prolongation of survival may be due to anti-inflammatory effects, because pancaspase inhibitors block interleukin-1-converting enzyme (later renamed caspase 1), an enzyme involved in activating interleukin-1 and some other proinflammatory cytokines. ${ }^{88}$ Apoptosis in a pathophysiological setting often promotes inflammation, ${ }^{89}$ which in turn can extend and accelerate tissue injury. ${ }^{17}$ During Listeria infection, hepatocellular apoptosis can promote neutrophil recruitment into the liver. ${ }^{90}$ Moreover, TNFinduced parenchymal apoptosis triggers neutrophil transmigration and massive aggravation of the injury in an endotoxemia model. ${ }^{91,92}$ Although the exact signaling mechanisms are not completely understood, apoptotic hepatocytes generate $\mathrm{CXC}$ chemokines, ${ }^{93}$ which can signal neutrophil infiltration. A proinflammatory role of apoptosis in hepatic ischemia/reperfusion injury is also implied by findings that pancaspase inhibition decreases neutrophil recruitment into the liver, with attenuation of reperfusion injury. ${ }^{94}$ Thus, apoptosis, even if limited to a relatively small number of cells, still has the potential to affect overall injury by contributing to the amplification of the inflammatory response.

\section{Necrapoptosis}

Part of the confusion concerning the roles of apoptosis and necrosis in ischemia/reperfusion and other forms of hepatic injury arises from the assumption that apoptotic and necrotic mechanisms are distinct and separate when, in fact, these mechanisms can be shared. In particular, the MPT plays an important role in oncotic necrosis, as well as in apoptosis. In ischemia, anaerobic glycolysis and ATP hydrolysis during ischemia rapidly decrease tissue $\mathrm{pH}$, which protects strongly against necrotic cell killing despite profound ATP depletion. ${ }^{95,96}$ Payback occurs when physiological $\mathrm{pH}$ returns after reperfusion, and the recovery of normal intracellular $\mathrm{pH}$ is an independent factor for precipitating lethal cellular reperfusion injury. ${ }^{70,71,97}$ The mechanism of $\mathrm{pH}$-dependent reperfusion injury involves onset of the MPT, a phenomenon that is inhibited by $\mathrm{pH}<7$. Initially after reperfusion of hepatocytes in a cell culture model, mitochondria begin to repolarize, but as the intracellular $\mathrm{pH}$ approaches 7 , mitochondria undergo inner membrane permeabilization, depolarization, and large-amplitude swelling. ${ }^{72}$

After onset of the MPT, mitochondrial uncoupling and activation of the mitochondrial uncoupler-stimulated adenosine triphosphatase lead to profound ATP depletion and ATP depletion-dependent necrotic cell death. ${ }^{72}$ Cyclosporin A, a specific inhibitor of the MPT, prevents MPT-induced mitochondrial depolarization, inner membrane permeabilization, and ATP exhaustion after reperfusion and blocks the necrotic cell killing that ensues. The importance of ATP depletion is illustrated by the ability of the ATP-generating glycolytic substrate fructose to prevent this necrotic cell death. Only $15 \%$ to $20 \%$ of normal ATP is sufficient to prevent such necrotic cell killing. ${ }^{98,99}$ Cytoprotection by fructose is downstream of the MPT, because fructose does not prevent the mitochondrial depolarization and inner membrane permeabilization induced by MPT-inducing treatments. ${ }^{100}$ MPT-dependent necrotic cell death in models of ischemia/reperfusion to cultured hepatocytes is not blocked by caspase inhibitors and occurs without TUNEL staining. ${ }^{101}$ The absence of TUNEL staining may reflect the release and dilution into the medium of nucleases after plasma membrane permeabilization.

However, when necrotic cell death is prevented by fructose, caspase 3-dependent apoptosis occurs instead, as documented by nuclear morphology, TUNEL labeling, and caspase activation. ${ }^{101}$ Cyclosporin A, a specific 
blocker of the MPT, still prevents this apoptosis, as do caspase inhibitors. Thus, the MPT is an obligatory event in both necrotic and apoptotic cell killing after ischemia/ reperfusion. But how can one event, the MPT, lead to two such disparate events?

The onset of MPT leads to large-amplitude mitochondrial swelling, rupture of the outer membrane, and release of cytochrome $c$ and other proteins from the intermembrane space between the mitochondrial inner and outer membranes. As discussed previously, cytochrome $c$ interacts with apoptosis-activating factor- 1 to promote caspase 9 activation, which then activates caspase 3 . However, cytochrome $c$-dependent activation of caspase 9 requires ATP or the less abundant deoxyadenosine triphosphate. ${ }^{42}$ Accordingly, the presence or absence of ATP can act as a "switch" between apoptosis and necrosis. ${ }^{102-104}$ When reperfusion leads to both MPT onset and ATP depletion, apoptotic signaling is blocked at the level of the apoptosome, and necrosis occurs as a direct result of the failure of ATP regeneration (Figure 5). By contrast, if glycolytic substrate is available, profound ATP depletion is prevented, and necrosis does not occur. Instead, ATP-dependent apoptotic signaling occurs that is initiated by cytochrome $c$ release after mitochondrial swelling. In cell-free extracts, the apparent $K_{M}$ of ATP for activating apoptosomes is approximately $0.4 \mathrm{mmol} /$ $\mathrm{L},{ }^{105,106}$ which is only approximately $10 \%$ of the ATP concentration of normoxic hepatocytes. Thus, the amount of ATP needed to prevent necrosis $(15 \%-20 \%$ of normoxic levels) is more than enough to permit cytochrome $c$-dependent caspase 9 and caspase 3 activation. Similarly, in hepatocytes exposed to calcium ionophore, the balance between ATP depletion after the MPT and ATP generation by glycolysis determines whether necrotic or apoptotic cell death occurs. ${ }^{100}$ Thus, one mitochondrial event, the MPT, can lead to both apoptosis and necrosis (Figure 5). Consistent with these in vitro findings, the mode of hepatic cell death can be apoptosis after resuscitation after a shorter period of hemorrhagic shock when cellular ATP levels fully recover but can be oncotic necrosis after a longer period of shock when ATP levels remain suppressed after resuscitation. ${ }^{102}$

Just as a necrotic process can be converted to an apoptotic one, a process that starts with classic apoptotic signaling may switch to necrosis if ATP depletion or another change leads to breakdown of the plasma membrane permeability barrier. Apoptosis resulting in such secondary necrosis typically occurs during Fas antibodyinduced hepatocellular injury in vivo. ${ }^{34}$ In Fas receptor ligation-dependent liver injury, mitochondrial cytochrome $c$ release, activation of the caspase cascade, DNA

\section{Necrapoptosis}

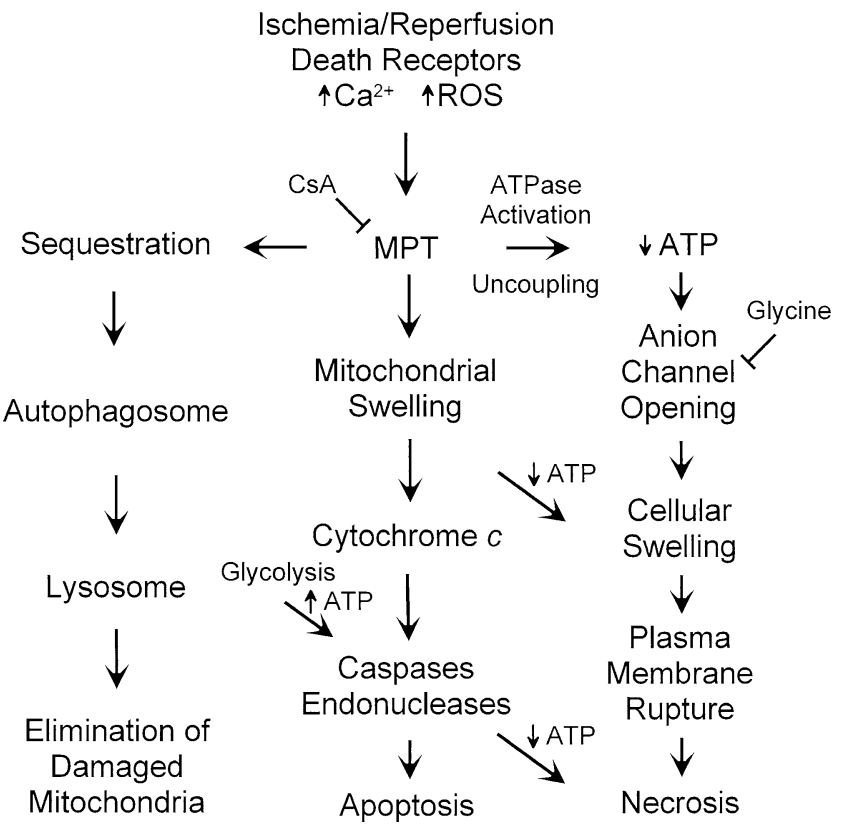

Figure 5. Scheme of mitochondrial permeability transition (MPT)dependent events in necrapoptosis. Ischemia/reperfusion, deathreceptor activation, mitochondrial $\mathrm{Ca}^{2+}$ loading, and reactive oxygen species (ROS) are some of the events that promote onset of the MPT. If MPT onset occurs in relatively few mitochondria, the organelles become sequestered into autophagosomes for lysosomal digestion, a process that eliminates the damaged and potentially toxic mitochondria. When the MPT involves more mitochondria, mitochondrial swelling leads to outer membrane rupture and cytochrome $c$ release. Provided that ATP is available from glycolysis and still-intact mitochondria, cytochrome $c$ activates downstream caspases and other executioner enzymes of apoptosis. When MPT onset is abrupt and involves most mitochondria, ATP becomes profoundly depleted, which blocks caspase activation. Instead, ATP depletion leads to the opening of a glycine-sensitive organic anion channel to initiate a metastable state that culminates with plasma membrane rupture and the onset of necrotic cell death. If ATP depletion occurs during downstream apoptotic signaling, then secondary necrosis may supervene. CsA, cyclosporin A.

fragmentation, and morphological changes characteristic of apoptosis occur before the onset of secondary necrosis, with hepatocellular enzyme release and inflammatory changes. ${ }^{34,78,79}$ Thus, in an apoptotic process that ultimately culminates in secondary necrosis, apoptotic mechanisms nonetheless remain clearly identifiable by morphological and biochemical parameters at earlier times.

The ability of a necrotic process to be converted to an apoptotic one and vice versa illustrates that apoptotic and necrotic cell death are not necessarily distinct and independent events. To the contrary, pathways leading to necrosis and apoptosis can be shared, a phenomenon called necrapoptosis or aponecrosis. ${ }^{107,108}$ In necrapoptosis, events such as the MPT initiate a chain reaction that 
culminates in either apoptosis or necrosis, depending on other variables, such as ATP supply (Figure 5). By inducing the MPT, ischemia/reperfusion causes both apoptosis and necrosis, although in a particular circumstance one or the other may predominate. The concept of necrapoptosis explains why features of apoptosis and necrosis often coexist in liver and other tissues, especially after pathologic insults such as ischemia/reperfusion or druginduced liver injury. Recent work also suggests that limited onset of the MPT induces autophagy, a process by which effete, damaged, or superfluous mitochondria and other organelles are eliminated from cells by lysosomal degradation. ${ }^{109}$ Thus, the concept of MPT-dependent necrapoptosis explains how injury can progress from reversible changes associated with tissue repair to apoptosis and then to necrosis. When the MPT occurs in only a few mitochondria, autophagy is stimulated, and the involved mitochondria are segregated for lysosomal degradation without stimulation of apoptotic signaling. With greater injury and more widespread MPT induction, apoptosis develops because of cytochrome $c$-dependent caspase activation. With even greater injury and MPT induction, ATP decreases to levels that no longer support apoptotic signaling, and oncotic necrosis develops instead (Figure 5).

\section{Conclusions}

In liver, oncotic necrosis and apoptosis share features and mechanisms. DNA degradation after necrosis causes TUNEL labeling, which may be incorrectly interpreted as apoptotic cell death. During apoptosis in pathophysiological settings, inflammatory responses and enzyme release occur that resemble a necrotic process. Frequently, oncotic necrosis and apoptosis coexist after toxic, hypoxic, and inflammatory liver injury. The coexistence of the 2 patterns of cell death likely reflects shared mechanistic pathways. Experimental or clinical settings will determine whether cells die predominantly by apoptosis or oncotic necrosis. Therefore, it is important to evaluate critical cell death pathways under clinically relevant conditions to discover new therapeutic intervention strategies in hepatic ischemia/reperfusion injury.

\section{References}

1. Strasberg SM. Preservation injury and donor selection: it all starts here. Liver Transpl Surg 1997;5(suppl 1):S1-S7.

2. Jaeschke $\mathrm{H}$. Mechanisms of reperfusion injury after warm ischemia of the liver. J Hepatobiliary Pancreat Surg 1998;21: 402-408.

3. Bilzer M, Gerbes AL. Preservation injury of the liver: mechanisms and novel therapeutic strategies. J Hepatol 2000;32:508-515.

4. Menger MD, Vollmar B. Role of microcirculation in transplantation. Microcirculation 2000;7:291-306.
5. Lemasters JJ. Hypoxic, ischemic, and reperfusion injury to liver. In: Arias IM, ed. The liver: biology and pathobiology. 4th ed. Philadelphia: Lippincott Williams \& Wilkins, 2001:257-279.

6. Jaeschke H. Molecular mechanisms of hepatic ischemia-reperfusion injury and preconditioning. Am J Physiol 2003;284:G15G26.

7. Caldwell-Kenkel JC, Currin RT, Tanaka Y, Thurman RG, Lemasters JJ. Reperfusion injury to endothelial cells following cold storage of rat liver. Hepatology 1989;10:292-299.

8. Lemasters JJ. The mitochondrial permeability transition and the calcium, oxygen and $\mathrm{pH}$ paradoxes: one paradox after another. Cardiovasc Res 1999;44:470-473.

9. Lemasters JJ, Caldwell-Kenkel JC, Currin RT, Tanaka Y, Marzi I, Thurman RG. Endothelial cell killing and activation of Kupffer cells following reperfusion of rat livers stored in Euro-Collins solution. In: Wisse E, Knook DL, Decker K, eds. Cells of the hepatic sinusoid. Volume 2. Rijswijk, The Netherlands: Kupffer Cell Foundation, 1989:277-280.

10. Jaeschke H, Farhood A. Neutrophil and Kupffer cell-induced oxidant stress and ischemia-reperfusion injury in rat liver in vivo. Am J Physiol 1991;260:G355-G362.

11. Jaeschke H, Bautista AP, Spolarics Z, Spitzer JJ. Superoxide generation by Kupffer cells and priming of neutrophils during reperfusion after hepatic ischemia. Free Radic Res Commun 1991;15:277-284.

12. Lindert KA, Caldwell-Kenkel JC, Nukina S, Lemasters JJ, Thurman RG. Activation of Kupffer cells on reperfusion following hypoxia: particle phagocytosis in a low-flow, reflow model. Am J Physiol 1992;262:G345-G350.

13. Liu P, McGuire GM, Fisher MA, Farhood A, Smith CW, Jaeschke $\mathrm{H}$. Activation of Kupffer cells and neutrophils for reactive oxygen formation is responsible for endotoxin-enhanced liver injury after hepatic ischemia. Shock 1995;3:56-62.

14. Lichtman SN, Lemasters JJ. Role of cytokines and cytokineproducing cells in reperfusion injury to the liver. Semin Liver Dis 1999;19:171-187.

15. Jaeschke H, Farhood A, Bautista AP, Spolarics Z, Spitzer JJ. Complement activates Kupffer cells and neutrophils during reperfusion after hepatic ischemia. Am J Physiol 1993;264: G801-G809.

16. Colletti LM, Remick DG, Burtch GD, Kunkel SL, Strieter RM, Campbell DA Jr. Role of tumor necrosis factor-alpha in the pathophysiologic alterations after hepatic ischemia/reperfusion injury in the rat. J Clin Invest 1990;85:1936-1943.

17. Jaeschke H, Farhood A, Smith CW. Neutrophils contribute to ischemia/reperfusion injury in rat liver in vivo. FASEB J 1990; 4:3355-3359.

18. Jaeschke H, Bautista AP, Spolarics Z, Spitzer JJ. Superoxide generation by neutrophils and Kupffer cells during in vivo reperfusion after hepatic ischemia in rats. J Leukoc Biol 1992;52: 377-382.

19. Jaeschke H, Farhood A, Bautista AP, Spolarics Z, Spitzer JJ, Smith CW. Functional inactivation of neutrophils with a Mac-1 (CD11b/CD18) monoclonal antibody protects against ischemiareperfusion injury in rat liver. Hepatology 1993;17:915-923.

20. Mavier P, Preaux A-M, Guigui B, Lescs MC, Zafrani ES, Dhumeaux D. In vitro toxicity of polymorphonuclear neutrophils to rat hepatocytes: evidence for a proteinase-mediated mechanism. Hepatology 1988;8:254-258.

21. Pannen BH, Al-Adili F, Bauer M, Clemens MG, Geiger KK. Role of endothelins and nitric oxide in hepatic reperfusion injury in the rat. Hepatology 1998;27:755-764.

22. Vollmar B, Glasz J, Leiderer R, Post S, Menger MD. Hepatic microcirculatory perfusion failure is a determinant of liver dysfunction in warm ischemia-reperfusion. Am J Pathol 1994;145: 1421-1431.

23. Gottlieb RA, Burleson KO, Kloner RA, Babior BM, Engler RL. 
Reperfusion injury induces apoptosis in rabbit cardiomyocytes. J Clin Invest 1994;94:1621-1628.

24. Sasaki H, Matsuno T, Tanaka N, Orita K. Activation of apoptosis during the reperfusion phase after rat liver ischemia. Transplant Proc 1996;28:1908-1909.

25. Gao W, Bentley RC, Madden JF, Clavien PA. Apoptosis of sinusoidal endothelial cells is a critical mechanism of preservation injury in rat liver transplantation. Hepatology 1998;27:16521660.

26. Trump BF, Goldblatt PJ, Stowell RE. Studies of necrosis in vitro of mouse hepatic parenchymal cells. Ultrastructural alterations in endoplasmic reticulum, Golgi apparatus, plasma membrane, and lipid droplets. Lab Invest 1965;14:2000-2028.

27. Lemasters JJ, DiGuiseppi J, Nieminen A-L, Herman B. Blebbing, free $\mathrm{Ca}^{++}$and mitochondrial membrane potential preceding cell death in hepatocytes. Nature 1987;325:78-81.

28. Nieminen AL, Gores GJ, Wray BE, Tanaka Y, Herman B, Lemasters JJ. Calcium dependence of bleb formation and cell death in hepatocytes. Cell Calcium 1988;9:237-246.

29. Zahrebelski G, Nieminen AL, Al-Ghoul K, Qian T, Herman B, Lemasters JJ. Progression of subcellular changes during chemical hypoxia to cultured rat hepatocytes: a laser scanning confocal microscopic study. Hepatology 1995;21:1361-1372.

30. Nishimura Y, Lemasters JJ. Glycine blocks opening of a death channel in cultured hepatic sinusoidal endothelial cells during chemical hypoxia. Cell Death Differ 2001;8:850-858.

31. Majno G, Joris I. Apoptosis, oncosis, and necrosis. An overview of cell death. Am J Pathol 1995;146:3-15.

32. Kerr JF, Wyllie AH, Currie AR. Apoptosis: a basic biological phenomenon with wide-ranging implications in tissue kinetics. Br J Cancer 1972;26:239-257.

33. Camilleri-Broet S, Vanderwerff H, Caldwell E, Hockenbery D. Distinct alterations in mitochondrial mass and function characterize different models of apoptosis. Exp Cell Res 1998;239: 277-292.

34. Ogasawara J, Watanabe-Fukunage R, Adachi M, Matsuzawa A, Kasugai T, Kitamura Y, Itoh N, Suda T, Nagata S. Lethal effect of the anti-Fas antibody in mice. Nature 1993;364:806-809.

35. Peter ME, Krammer PH. Mechanisms of CD95 (APO-1/Fas)mediated apoptosis. Curr Opin Immunol 1998;10:545-551.

36. Vieira HL, Kroemer G. Pathophysiology of mitochondrial cell death control. Cell Mol Life Sci 1999;56:971-976.

37. Lemasters JJ, Qian T, He L, Kim J-S, Elmore SP, Cascio WE, Brenner DA. Role of mitochondrial inner membrane permeabilization in necrotic cell death, apoptosis and autophagy. Antioxid Redox Signal 2002;4:769-781.

38. Gross A, McDonnell JM, Korsmeyer SJ. Bcl-2 family members and the mitochondria in apoptosis. Genes Dev 1999;13:18991911.

39. Cohen GM. Caspases: the executioners of apoptosis. Biochem J 1997;326:1-16.

40. Scaffidi C, Fulda S, Srinivasan A, Friesen C, Li F, Tomaselli KJ, Debatin KM, Krammer PH, Peter ME. Two CD95 (APO-1/Fas) signaling pathways. EMBO J 1998;17:1675-1687.

41. Yin XM. Bid, a critical mediator for apoptosis induced by the activation of Fas/TNF-R1 death receptors in hepatocytes. J Mol Med 2000;78:203-211.

42. Liu X, Kim CN, Yang J, Jemmerson R, Wang X. Induction of apoptotic program in cell-free extracts: requirement for dATP and cytochrome c. Cell 1996;86:147-157.

43. Cande C, Cohen I, Daugas E, Ravagnan L, Larochette N, Zamzami N, Kroemer G. Apoptosis-inducing factor (AIF): a novel caspase-independent death effector released from mitochondria. Biochimie 2002;84:215-222.

44. Du C, Fang M, Li Y, Li L, Wang X. Smac, a mitochondrial protein that promotes cytochrome c-dependent caspase activation by eliminating IAP inhibition. Cell 2000;102:33-42.
45. Verhagen AM, Ekert PG, Pakusch M, Silke J, Connolly LM, Reid GE, Moritz RL, Simpson RJ, Vaux DL. Identification of DIABLO, a mammalian protein that promotes apoptosis by binding to and antagonizing IAP proteins. Cell 2000;102:43-53.

46. Bernardi P. Mitochondrial transport of cations: channels, exchangers, and permeability transition. Physiol Rev 1999;79: 1127-1155.

47. Shimizu S, Ide T, Yanagida T, Tsujimoto Y. Electrophysiological study of a novel large pore formed by Bax and the voltagedependent anion channel that is permeable to cytochrome $\mathrm{C}$. J Biol Chem 2000;275:12321-12325.

48. Korsmeyer SJ, Wei MC, Saito M, Weiler S, Oh KJ, Schlesinger $\mathrm{PH}$. Pro-apoptotic cascade activates BID, which oligomerizes BAK or BAX into pores that result in the release of cytochrome c. Cell Death Differ 2000;7:1166-1173.

49. Wang $X$. The expanding role of mitochondria in apoptosis. Genes Dev 2001;15:2922-2933.

50. Hatano E, Bradham CA, Stark A, limuro Y, Lemasters JJ, Brenner DA. The mitochondrial permeability transition augments Fasinduced apoptosis in mouse hepatocytes. J Biol Chem 2000; 275:11814-11823.

51. Bredesen DE. Apoptosis: overview and signal transduction pathways. J Neurotrauma 2000;17:801-810.

52. Schwabe RF, Bennett BL, Manning AM, Brenner DA. Differential role of I kappa B kinase 1 and 2 in primary rat hepatocytes. Hepatology 2001;33:81-90.

53. Chen G, Goeddel DV. TNF-R1 signaling: a beautiful pathway. Science 2002;296:1634-1635.

54. Bradham CA, Qian T, Streetz K, Trautwein C, Brenner DA, Lemasters $\mathrm{JJ}$. The mitochondrial permeability transition is required for tumor necrosis factor alpha-mediated apoptosis and cytochrome c release. Mol Cell Biol 1998;18:6353-6364.

55. Bedner E, Li X, Gorczyca W, Melamed MR, Darzynkiewicz Z. Analysis of apoptosis by laser scanning cytometry. Cytometry 1999;35:181-195.

56. Dong Z, Saikumar P, Weinberg JM, Venkatachalam MA. Internucleosomal DNA cleavage triggered by plasma membrane damage during necrotic cell death. Involvement of serine but not cysteine proteases. Am J Pathol 1997;151:1205-1213.

57. Ray SD, Sorge CL, Raucy JL, Corcoran GB. Early loss of large genomic DNA in vivo with accumulation of $\mathrm{Ca}^{2+}$ in the nucleus during acetaminophen-induced liver injury. Toxicol Appl Pharmacol 1990;106:346-351.

58. Shen W, Kamendulis LM, Ray SD, Corcoran GB. Acetaminopheninduced cytotoxicity in cultured mouse hepatocytes: effects of $\mathrm{Ca}(2+)$-endonuclease, DNA repair, and glutathione depletion inhibitors on DNA fragmentation and cell death. Toxicol Appl Pharmacol 1992;112:32-40.

59. Grasl-Kraupp B, Ruttkay-Nedecky B, Koudelka H, Bukowska K, Bursch W, Schulte-Hermann R. In situ detection of fragmented DNA (TUNEL assay) fails to discriminate among apoptosis, necrosis, and autolytic cell death: a cautionary note. Hepatology 1995;21:1465-1468.

60. Ohno M, Takemura G, Ohno A, Misao J, Hayakawa Y, Minatoguchi S, Fujiwara T, Fujiwara H. "Apoptotic" myocytes in infarct area in rabbit hearts may be oncotic myocytes with DNA fragmentation: analysis by immunogold electron microscopy combined with in situ nick end-labeling. Circulation 1998;98:14221430.

61. Gujral JS, Knight TR, Farhood A, Bajt ML, Jaeschke H. Mode of cell death after acetaminophen overdose in mice: apoptosis or oncotic necrosis? Toxicol Sci 2002;67:322-328.

62. Banasiak KJ, Xia Y, Haddad GG. Mechanisms underlying hypoxia-induced neuronal apoptosis. Prog Neurobiol 2000; 62:215-249.

63. Sheridan AM, Bonventre JV. Cell biology and molecular mecha- 
nisms of injury in ischemic acute renal failure. Curr Opin Nephrol Hypertens 2000;9:427-434.

64. Borghi-Scoazec G, Scoazec JY, Durand F, Bernuau J, Belghiti J, Feldmann G, Henin D, DeGott C. Apoptosis after ischemiareperfusion in human liver allografts. Liver Transpl Surg 1997; 3:407-415.

65. Kohli V, Selzner M, Madden JF, Bentley RC, Clavien PA. Endothelial cell and hepatocyte deaths occur by apoptosis after ischemia-reperfusion injury in the rat liver. Transplantation 1999;67:1099-1105.

66. Cursio R, Gugenheim J, Ricci JE, Crenesse D, Rostagno P, Maulon L, Saint-Paul MC, Ferrua B, Auberger AP. A caspase inhibitor fully protects rats against lethal normothermic liver ischemia by inhibition of liver apoptosis. FASEB J 1999;13: 253-261.

67. Natori S, Selzner M, Valentino KL, Fritz LC, Srinivasan A, Clavien PA, Gores GJ. Apoptosis of sinusoidal endothelial cells occurs during liver preservation injury by a caspase-dependent mechanism. Transplantation 1999;68:89-96.

68. Sindram D, Porte RJ, Hoffman MR, Bentley RC, Clavien PA. Platelets induce sinusoidal endothelial cell apoptosis upon reperfusion of the cold ischemic rat liver. Gastroenterology 2000;118:183-191.

69. Sindram D, Porte RJ, Hoffman MR, Bentley RC, Clavien PA. Synergism between platelets and leukocytes in inducing endothelial cell apoptosis in the cold ischemic rat liver: a Kupffer cell-mediated injury. FASEB J 2001;15:1230-1232.

70. Caldwell-Kenkel JC, Thurman RG, Lemasters JJ. Selective loss of nonparenchymal cell viability after cold, ischemic storage of rat livers. Transplantation 1988;45:834-837.

71. Currin RT, Gores GJ, Thurman RG, Lemasters JJ. Protection by acidotic $\mathrm{pH}$ against anoxic cell killing in perfused rat liver: evidence for a 'pH paradox'. FASEB J 1991;5:207-210.

72. Qian T, Nieminen AL, Herman B, Lemasters JJ. Mitochondrial permeability transition in $\mathrm{pH}$-dependent reperfusion injury to rat hepatocytes. Am J Physiol 1997;273:C1783-C1792.

73. Bradford BU, Marotto M, Lemasters JJ, Thurman RG. New simple models to evaluate zone-specific damage to hypoxia in the perfused rat liver: time course and effect of nutritional state. J Pharmacol Exp Ther 1986;236:263-268.

74. Gujral JS, Bucci TJ, Farhood A, Jaeschke H. Mechanism of cell death during hepatic ischemia-reperfusion in rats: apoptosis or necrosis? Hepatology 2001;33:397-405.

75. Redaelli CA, Tian YH, Schaffner T, Ledermann M, Baer HU, Dufour JF. Extended preservation of rat liver graft by induction of heme oxygenase-1. Hepatology 2002;35:1082-1092.

76. Rentsch M, Beham A, lesalnieks I, Mirwald T, Anthuber M, Jauch $\mathrm{KW}$. Impact of prolonged cold ischemia and reperfusion on apoptosis, activation of caspase 3 , and expression of bax after liver transplantation in the rat. Transplant Proc 2001;33:850851.

77. Ikebe N, Akaike T, Miyamoto Y, Hayashida K, Yoshitake J, Ogawa M, Maeda H. Protective effect of S-nitrosylated-protease inhibitor on hepatic ischemia-reperfusion injury. J Pharmacol Exp Ther 2000;295:904-911.

78. Bajt ML, Lawson JA, Vonderfecht SL, Gujral JS, Jaeschke H. Protection against Fas receptor-mediated apoptosis in hepatocytes and nonparenchymal cells by a caspase-8 inhibitor in vivo: evidence for postmitochondrial processing of caspase-8. Toxicol Sci 2000;58:109-117.

79. Bajt ML, Vonderfecht SL, Jaeschke H. Differential protection with inhibitors of caspase- 8 and caspase- 3 in murine models of tumor necrosis factor and Fas receptor-mediated hepatocellular apoptosis. Toxicol Appl Pharmacol 2001;175:243-252.

80. Lawson JA, Fisher MA, Simmons CA, Farhood A, Jaeschke H. Inhibition of Fas receptor (CD95)-induced hepatic caspase acti- vation and apoptosis by acetaminophen in mice. Toxicol Appl Pharmacol 1999;156:179-186.

81. Gujral JS, Farhood A, Jaeschke H. Oncotic necrosis and caspase-dependent apoptosis during galactosamine-induced liver injury in rats. Toxicol Appl Pharmacol 2003;190:37-46.

82. Bilbao G, Contreras JL, Eckhoff DE, Mikheeva G, Krasnykh V, Douglas JT, Thomas FT, Thomas JM, Curiel DT. Reduction of ischemia-reperfusion injury of the liver by in vivo adenovirusmediated gene transfer of the antiapoptotic $\mathrm{Bcl}-2$ gene. Ann Surg 1999;230:185-193.

83. Lacronique V, Mignon A, Fabre M, Viollet B, Rouquet N, Molina T, Porteu A, Henrion A, Bouscary D, Varlet P, Joulin V, Kahn A. $\mathrm{Bcl}-2$ protects from lethal hepatic apoptosis induced by an anti-Fas antibody in mice. Nat Med 1996;2:80-86.

84. Yamabe K, Shimizu S, Kamiike W, Waguri S, Eguchi Y, Hasegawa J, Okuno S, Yoshioka $Y$, Ito T, Sawa $Y$, Uchiyama $Y$, Tsujimoto Y, Matsuda H. Prevention of hypoxic liver cell necrosis by in vivo human $\mathrm{bcl}-2$ gene transfection. Biochem Biophys Res Commun 1998;243:217-223.

85. Kane DJ, Ord T, Anton R, Bredesen DE. Expression of $b c l-2$ inhibits necrotic neural cell death. J Neurosci Res 1995;40: 269-275.

86. Adams ML, Pierce RH, Vail ME, White CC, Tonge RP, Kavanagh TJ, Fausto N, Nelson SD, Bruschi SA. Enhanced acetaminophen hepatotoxicity in transgenic mice overexpressing $\mathrm{Bcl}-2$. Mol Pharmacol 2001:60:907-915.

87. Knight TR, Jaeschke H. Acetaminophen-induced inhibition of Fas receptor-mediated liver cell apoptosis: mitochondrial dysfunction versus glutathione depletion. Toxicol Appl Pharmacol 2002; 181:133-141.

88. Siegmund B. Interleukin-1beta converting enzyme (caspase-1) in intestinal inflammation. Biochem Pharmacol 2002;64:1-8.

89. Jaeschke H. Inflammation in response to hepatocellular apoptosis. Hepatology 2002;35:964-966.

90. Rogers HW, Callery MP, Deck B, Unanue ER. Listeria monocytogenes induces apoptosis of infected hepatocytes. J Immunol 1996;156:679-684.

91. Jaeschke H, Fisher MA, Lawson JA, Simmons CA, Farhood A, Jones DA. Activation of caspase-3 (CPP32)-like proteases is essential for TNF- $\alpha$-induced hepatic parenchymal cell apoptosis and neutrophil-mediated necrosis in a murine endotoxin shock model. J Immunol 1998;160:3480-3486.

92. Lawson JA, Fisher MA, Simmons CA, Farhood A, Jaeschke H. Parenchymal cell apoptosis as a signal for sinusoidal sequestration and transendothelial migration of neutrophils in murine models of endotoxin- and Fas-antibody-mediated liver injury. Hepatology 1998;28:761-767.

93. Faouzi S, Burckhardt BE, Hanson JC, Campe CB, Schrum LW, Rippe RA, Maher JJ. Anti-Fas induces hepatic chemokines and promotes inflammation by an NF-кB-independent, caspase-3dependent pathway. J Biol Chem 2001;276:49077-49082.

94. Kobayashi A, Imamura H, Isobe M, Matsuyama $\mathrm{Y}$, Soeda J, Matsunaga K, Kawasaki S. Mac-1 (CD11b/CD18) and intercellular adhesion molecule-1 in ischemia-reperfusion injury of rat liver. Am J Physiol 2001;281:G577-G585.

95. Gores GJ, Nieminen AL, Fleishman KE, Dawson TL, Herman B, Lemasters JJ. Extracellular acidosis delays onset of cell death in ATP-depleted hepatocytes. Am J Physiol 1988;255:C315C322.

96. Gores GJ, Nieminen A-L, Wray BE, Herman B, Lemasters JJ. Intracellular $\mathrm{pH}$ during "chemical hypoxia" in cultured rat hepatocytes: protection by intracellular acidosis against the onset of cell death. J Clin Invest 1989;83:386-396.

97. Bond JM, Chacon E, Herman B, Lemasters JJ. Intracellular pH and $\mathrm{Ca}^{2+}$ homeostasis in the $\mathrm{pH}$ paradox of reperfusion injury to neonatal rat cardiac myocytes. Am J Physiol 1993;265:C129 C137. 
98. Anundi I, King J, Owen DA, Schneider H, Lemasters JJ, Thurman RG. Fructose prevents hypoxic cell death in liver. Am J Physiol 1987;253:G390-G396.

99. Nieminen AL, Saylor AK, Herman B, Lemasters JJ. ATP depletion rather than mitochondrial depolarization mediates hepatocyte killing after metabolic inhibition. Am J Physiol 1994;267:C67C74.

100. Qian T, Herman B, Lemasters JJ. The mitochondrial permeability transition mediates both necrotic and apoptotic death of hepatocytes exposed to Br-A23187. Toxicol Appl Pharmacol 1999; 154:117-125.

101. Kim J-S, Qian T, Lemasters JJ. ATP supply and the mitochondrial permeability transition in the switch from necrotic to apoptotic cell death after ischemia/reperfusion to cultured rat hepatocytes. Gastroenterology 2003;124:494-503.

102. Paxian M, Bauer I, Rensing $H$, Jaeschke $H$, Mautes AEM, Kolb SA, Wolf B, Stockhausen A, Jeblick S, Bauer M. Recovery of hepatocellular ATP and "pericentral apoptosis" after hemorrhage and resuscitation. FASEB J 2003;17:993-1002.

103. Richter C, Schweizer M, Cossarizza A, Franceschi C. Control of apoptosis by the cellular ATP level. FEBS Lett 1996;378:107110.

104. Leist M, Single B, Castoldi AF, Kuhnle S, Nicotera P. Intracellular adenosine triphosphate (ATP) concentration: a switch in the decision between apoptosis and necrosis. J Exp Med 1997; 185:1481-1486.

105. Eguchi Y, Shimizu S, Tsujimoto Y. Intracellular ATP levels deter- mine cell death fate by apoptosis or necrosis. Cancer Res 1997;57:1835-1840.

106. Genini D, Budihardjo I, Plunkett W, Wang X, Carrera CJ, Cottam HB, Carson DA, Leoni LM. Nucleotide requirements for the in vitro activation of the apoptosis protein-activating factor-1-mediated caspase pathway. J Biol Chem 2000;275:29-34.

107. Lemasters JJ. V. Necrapoptosis and the mitochondrial permeability transition: shared pathways to necrosis and apoptosis. Am J Physiol 1999;276:G1-G6.

108. Formigli L, Papucci L, Tani A, Schiavone N, Tempestini A, Orlandini GE, Capaccioli S, Orlandini SZ. Aponecrosis: morphological and biochemical exploration of a syncretic process of cell death sharing apoptosis and necrosis. J Cell Physiol 2000;182:4149.

109. Elmore SP, Qian T, Grissom SF, Lemasters JJ. The mitochondrial permeability transition initiates autophagy in rat hepatocytes. FASEB J 2001;15:2286-2287.

Received February 11, 2002. Accepted May 1, 2003.

Address requests for reprints to: Hartmut Jaeschke, Ph.D., Liver Research Institute, University of Arizona, College of Medicine, Room 6309, 1501 N. Campbell Avenue, Tucson, Arizona. e-mail: Jaeschke@email.arizona.edu; fax: (520) 626-5975.

Supported in part by National Institutes of Health grants ES06091 and AA12916 (to H.J.) and DK37034, DK59340, and AG13637 (to J.J.L.). 